\title{
Hydrogen isotope exchange in tungsten during annealing in hydrogen atmosphere
}

\section{Ahlgren, Tommy}

2019-02

Ahlgren , T , Jalkanen , P , Mizohata , K , Tuboltsev , V , Räisänen , J , Heinola , K \& Tikkanen , P O 2019 , ' Hydrogen isotope exchange in tungsten during annealing in hydrogen atmosphere ' , Nuclear Fusion, vol. 59 , no. 2 , 026016 . https://doi.org/10.1088/1741-4326/aaf6c9

http://hdl.handle.net/10138/310816

https://doi.org/10.1088/1741-4326/aaf6c9

cc_by_nc_nd

acceptedVersion

Downloaded from Helda, University of Helsinki institutional repository.

This is an electronic reprint of the original article.

This reprint may differ from the original in pagination and typographic detail.

Please cite the original version. 
Accepted for publication in Nuclear Fusion 7.12.2018

http://iopscience.iop.org/article/10.1088/1741-4326/aaf6c9

\title{
Hydrogen isotope exchange in tungsten during annealing in hydrogen atmosphere
}

\author{
T. Ahlgren, P. Jalkanen, K. Mizohata, V. Tuboltsev, J. \\ Räisänen, K. Heinola and P. Tikkanen \\ Accelerator Laboratory, University of Helsinki, P.O. Box 43, 00014, Finland \\ E-mail: tommy.ahlgren@helsinki.fi
}

\begin{abstract}
.
The radiological safety of the future thermonuclear fusion devices depends critically on the total tritium inventory in the plasma-facing components. The planned method to remove tritium from the ITER reactor tungsten divertor is to perform vacuum baking. We show that tritium removal from tungsten can be enhanced by the isotope exchange mechanism by doing the baking in $\mathrm{H}_{2}$ atmosphere. The results show that the retained deuterium from $30 \mathrm{keV}$ implantation can be expected to drop almost to zero after $24 \mathrm{~h}$ annealing at $250^{\circ} \mathrm{C}$ in $\mathrm{H}_{2}$ atmosphere. Annealing in vacuum requires temperatures above $400^{\circ} \mathrm{C}$ for close to zero retention.
\end{abstract}

Keywords: isotope exchange, tritium, retention, fusion, tungsten

\section{Introduction}

The safety of the future thermonuclear fusion devices and experimental and demonstrative reactors like ITER and DEMO depends largely on the total tritium (T) inventory in the plasma-facing components (PFCs). Methods to reduce this inventory includes the choice of the plasma-facing material and using different tritium removal techniques. The usual $\mathrm{T}$ removal method is to perform thermal treatments to detrap and remove trapped tritium from intrinsic and plasma-induced traps [1]. Another method to reduce $\mathrm{T}$ inventory is to locally heat the surface using high-power pulsed flashlamp irradiation [2] or the pulsed laser-induced desorption [3, 4]. A method that does not need high temperatures is the use of hydrogen isotope exchange, where another hydrogen isotope is introduced in the material by low energy implantation to replace the unwanted isotope in the material $[5,6,7]$. The above-mentioned methods all have some shortcomings or disadvantages. The thermal treatment requires relatively high temperatures to remove the major fraction of the trapped T, which in ITER and other 
large tokamaks is difficult due to the large component masses involved. In fact, the ITER strategy to remove and recover the trapped tritium from the plasma-facing components is to perform vacuum baking, at $240^{\circ} \mathrm{C}$ for the first wall and at $350^{\circ} \mathrm{C}$ for the tungsten (W) divertor [8]. The relatively low temperature of $350^{\circ} \mathrm{C}$ is shown to only remove about $40 \%$ of the retained deuterium (D) from the JET ITER-Like W divertor during annealing for $15 \mathrm{~h} \mathrm{[1]}$. Usually in the experiments the $\mathrm{T}$ is replaced by deuterium (D) for safety reasons. Significant laser-induced hydrogen desorption has been observed only when the sample surface temperature during the laser pulse is close to the melting point [9]. Also the removal efficiency from deeper in the component is unclear. Further, it has been shown that low energy (below displacement threshold energy) high flux hydrogen implantation creates hydrogen trapping defects in the near surface region $[10,11,12]$. Therefore, $\mathrm{T}$ isotope removal by isotope exchange mechanism by $\mathrm{H}$ irradiation might not be a viable method due to the subsequent increase of $\mathrm{T}$ trapping in the $\mathrm{H}$ induced traps [6].

In this study, we show that hydrogen isotope exchange in $\mathrm{W}$ also takes place during low temperature annealing in hydrogen atmosphere. Thus, $\mathrm{T}$ removal from $\mathrm{W}$ could be done at moderately low temperatures and without the need of $\mathrm{H}$ irradiation. At the least, the $\mathrm{T}$ retention after vacuum annealing in $\mathrm{W}$ could be further reduced by continuing the annealing in hydrogen atmosphere.

\section{Experimental}

\subsection{Material and D implantation}

The sample material is high purity $(99.99 \%)$ polycrystalline $\mathrm{W}$ sheet (thickness of 1 $\mathrm{mm}$ ) produced by Plansee AG (Reutte, Austria). The main impurities, excluding Mo, in the $\mathrm{W}$ samples are carbon $\sim 10 \mu \mathrm{g} / \mathrm{g}$ and oxygen $\sim 5 \mu \mathrm{g} / \mathrm{g}$, corresponding to about $10^{25}$ and $5 \times 10^{24}$ atoms $/ \mathrm{m}^{3}$, respectively. The sheet was cut into pieces $\left(10 \times 10 \mathrm{~mm}^{2}\right.$

) which were mirror-polished with colloidal silica (grain size of $\sim 0.05 \mu \mathrm{m}$ ), giving a surface roughness of less than about $10 \mathrm{~nm}$ root mean square [13]. The samples were then pre-annealed in a vacuum of $\sim 10^{-5} \mathrm{~Pa}$ at $1270 \mathrm{~K}$ for $2 \mathrm{~h}$ a priori implantation.

Deuterium implantation was done at room temperature using the $500 \mathrm{kV}$ accelerator at the university of Helsinki. Low flux $60 \mathrm{keV} \mathrm{D}_{2}^{+}$ions $(30 \mathrm{keV}$ per D atom) were implanted perpendicular to the surface in a vacuum of $\sim 10^{-6} \mathrm{~Pa}$. The implantation flux and dose was $3 \times 10^{17} \mathrm{D} /\left(\mathrm{m}^{2} \mathrm{~s}\right)$ and $5.8 \times 10^{20} \mathrm{D} / \mathrm{m}^{2}$, respectively. The beam was swept for homogeneous exposure over a $6 \mathrm{~cm}$ diameter implantation area, and the whole sample surface area was implanted. The sample was mounted on a large aluminium backing, which together with the very low implantation flux should not heat 
the sample noticeably over room temperature.

\subsection{Annealing}

The D implanted samples were annealed in a quartz tube furnace in close proximity $(\sim 1$ $\mathrm{mm}$ ) of a K-type thermocouple. The tube was pumped to a vacuum better than $10^{-2}$ $\mathrm{Pa}$ before heating. When annealing in $\mathrm{H}_{2}$ atmosphere was applied, the gas was let into the pre-pumped tube up to $1 \mathrm{~atm}$ pressure and then pumped down to $100 \mathrm{~Pa}$ with a membrane pump. After the $\mathrm{H}$ flushing procedure the pressure was slowly increased by adjusting the pumping speed to the $\mathrm{H}$ leak until $\sim 1$ atm $\mathrm{H}_{2}$ gas pressure was attained. Continuous $\mathrm{H}$ gas flushing was then maintained during the whole annealing.

Prior to inserting the quartz tube into the furnace, it was preheated 10-15 K over the target temperature. The tube was then inserted into the ceramic furnace and the desired temperature was achieved in about 1000-1500 seconds. A PID controller kept the temperature at the thermocouple within $\pm 3 \mathrm{~K}$ range with respect to the target temperature. The measurement time started as the temperature reached about $3 \mathrm{~K}$ from the desired value. The cooling was done rapidly by extruding the tube from the oven.

\subsection{Elastic recoil detection analysis}

ERDA was performed using $32 \mathrm{MeV}{ }^{35} \mathrm{Cl}$ ions from a $5 \mathrm{MV}$ tandem accelerator at University of Helsinki. Medium heavy ions were chosen to maximize yield, separation of $\mathrm{D}$ and $\mathrm{H}$ signals, and depth resolution at the surface, and to minimize irradiationinduced damage of the sample. An incident angle of $\alpha=60^{\circ}$ with respect to the sample surface normal was used and recoiled $\mathrm{H}$ and $\mathrm{D}$ atoms were detected in horizontal geometry under a scattering angle of $\Theta=50^{\circ}$. The ERDA detector has a nominal energy resolution of $15 \mathrm{keV}$ and was located at a distance of $45 \mathrm{~mm}$ from the target. Detector solid angle was limited with collimator aperture of $2 \mathrm{~mm}$ in width and $14 \mathrm{~mm}$ in height. Havar stopper foil of $4 \mu \mathrm{m}$ thickness was used for filtering of scattered ions and recoils other than $\mathrm{H}$ and $\mathrm{D}$. The depth resolution at the surface is about $50 \mathrm{~nm}$ and about $150 \mathrm{~nm}$ at the implantation depth calculated by WDepth code [14]. Maximum probing depth for $\mathrm{D}$ is $450 \mathrm{~nm}$ with the used beam and measurement geometry. Measurement data was collected in list mode to monitor $\mathrm{H}$ and $\mathrm{D}$ desorption during measurement. 


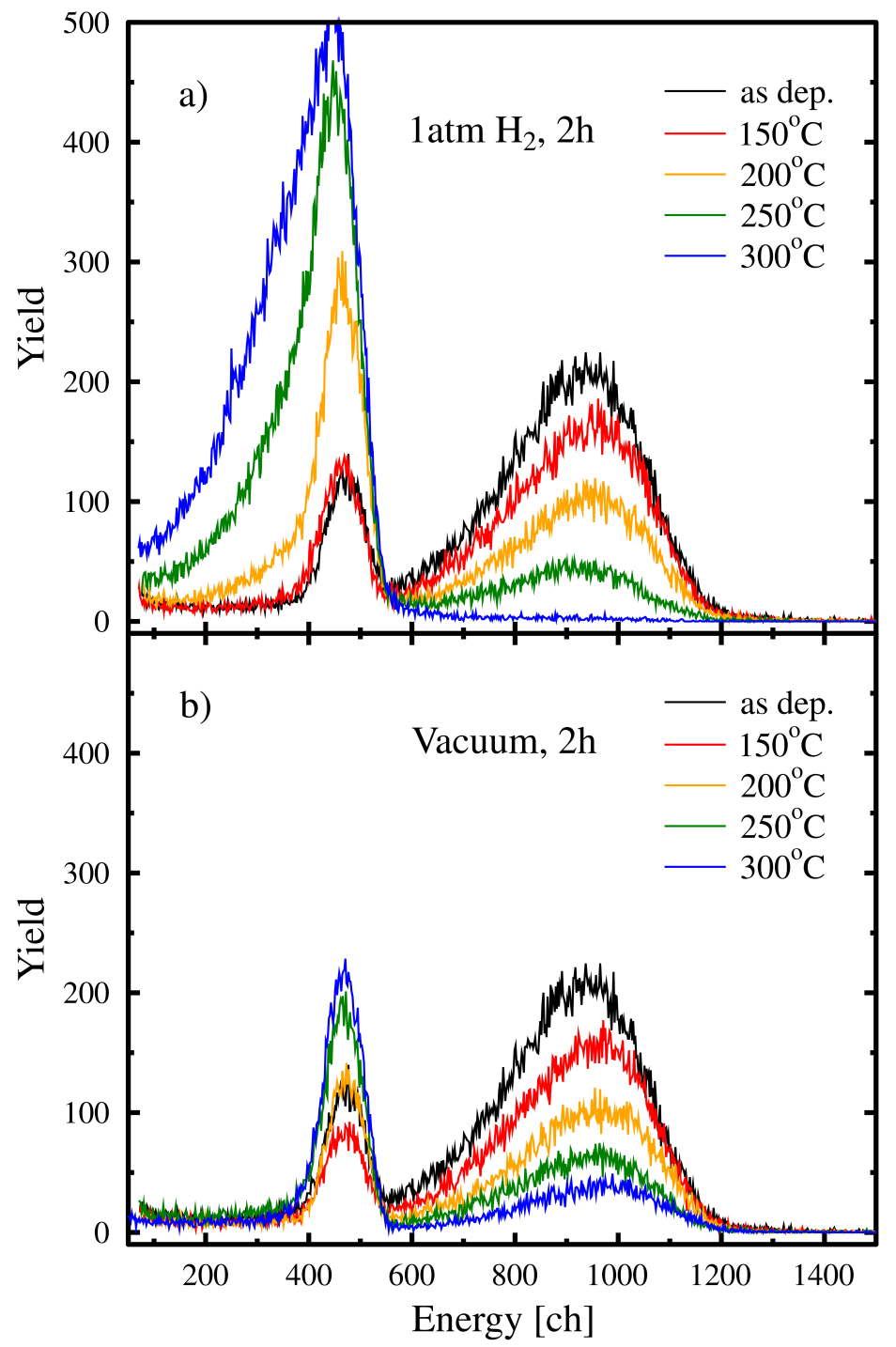

Figure 1. The ERDA spectra of the D implanted $\mathrm{W}$ annealed for $2 \mathrm{~h}$ at different temperatures in either vacuum or $\mathrm{H}_{2}$ atmosphere. The $\mathrm{D}$ signal is approximately between channels 500 (corresponding to a depth of $\sim 400 \mathrm{~nm}$ ) and 1200. The $\mathrm{H}$ signal is below channel $\sim 550$, with the surface $\mathrm{H}$ approximately between channels 400 and 550. a) annealing done in hydrogen atmosphere. b) annealing done in vacuum.

\section{Results and discussion}

The experimental ERDA spectra are shown in Figure 1. Figure 1 a) shows the D and $\mathrm{H}$ signal after $2 \mathrm{~h}$ annealing in hydrogen atmosphere, and b) the corresponding signals 
after annealing in vacuum. Each experiment was done on a different sample. We can see a decrease in the D signal for increasing annealing temperatures. Moreover, in the $\mathrm{H}_{2}$ gas annealing we can observe an increase in the $\mathrm{H}$ signal in the near surface region above temperatures of $200^{\circ} \mathrm{C}$. Even if the ERDA depth resolution is not good enough to resolve the surface $\mathrm{H}$ from the $\mathrm{H}$ in the bulk, the broadening and the increase of the $\mathrm{H}$ signal clearly indicates $\mathrm{H}$ diffusion into the bulk.

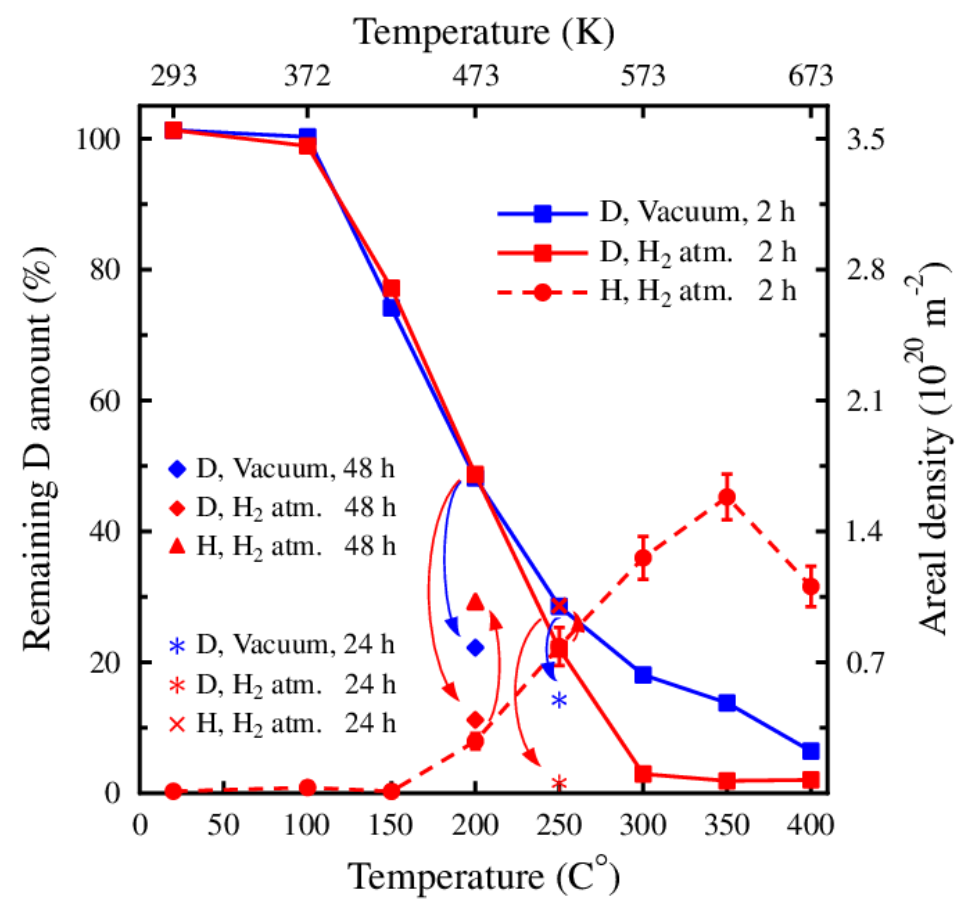

Figure 2. Remaining $\mathrm{D}$ and $\mathrm{H}$ amounts in the D-implanted depth region after annealing at different temperatures in either vacuum (blue) or $\mathrm{H}_{2}$ atmosphere (red). The amounts are integrated from the experimental ERDA spectra between depth region from zero to about $400 \mathrm{~nm}$. The surface $\mathrm{H}$ peak of about $0.2 \times 10^{20} / \mathrm{m}^{2}$ is excluded.

Figure 2 shows the remaining integrated D amount in the samples after annealing at different temperatures in either vacuum or $\mathrm{H}_{2}$ atmosphere. The amounts refer to the integrated signal obtained from the ERDA measurements. The approximate surface $\mathrm{H}$ amount, $(0.19 \pm 0.09) \times 10^{20} \mathrm{H} / \mathrm{m}^{2}$, not included in Fig. 2, for all temperatures is due to $\mathrm{H}$ atoms accumulated at the $\mathrm{W}$ surface during the room temperature normal atmosphere storage of the samples between the annealing and the ERDA measurements. This measured surface areal concentration is surprisingly close to both the theoretical and experimental value of $\sim 0.2 \times 10^{20} \mathrm{H} / \mathrm{m}^{2}$ for a full monolayer on the $\mathrm{W}$ (100) surface 
$[15,16]$. The errors for the $\mathrm{D}$ amounts are about of the size of the squares in the figure and comes from the square root of the signal areas and the small overlap of the D and $\mathrm{H}$ signals, see Figure 1. The errors for $\mathrm{H}$ amounts are considerably larger due to the overlap of the sub-surface $\mathrm{H}$ and $\mathrm{H}$ in the surface peak signals.

From the initial D fluence of $5.8 \times 10^{20} \mathrm{D} / \mathrm{m}^{2}$ about $10 \%\left(0.6 \times 10^{20} \mathrm{D} / \mathrm{m}^{2}\right)$ is directly reflected (backscattered) during the implantation according to SRIM-2013 simulations [17]. Hydrogen atoms are very mobile in $\mathrm{W}$ at room temperature with a migration barrier $\sim 0.25 \mathrm{eV}[18]$. Thus, all the measured hydrogen amounts seen in Fig. 2 are hydrogen being trapped in intrinsic or implantation-induced traps. We can see that about $1.7 \times 10^{20} \mathrm{D} / \mathrm{m}^{2}$ (additional to reflection) is missing from the implanted $\mathrm{D}$ amount. The major part of this missing D corresponds to out-diffusion from the sample surface and a minor part diffusion deeper into the sample during and directly after implantation. The remaining trapped (retained) D amount $\left(3.5 \times 10^{20} \mathrm{D} / \mathrm{m}^{2}\right)$ starts to decrease during annealing above temperature of about $100^{\circ} \mathrm{C}$ due to detrapping processes starting to take place as follows. D implantation in the keV/D energy range has been shown to produce mostly mono-vacancies to which D atoms trap [19]. Each mono-vacancy can trap at most five to six D atoms at room temperature, with decreasing binding energy for each additional $\mathrm{D}$ atom in the mono-vacancy [20, 21]. When the mono-vacancy traps five D atoms, the zero point energy corrected binding energy is about $1.0 \mathrm{eV}$ which leads to $\mathrm{D}$ detrapping above $100^{\circ} \mathrm{C}$ as shown in thermal desorption spectrometry experiments $[13,22]$. D detrapping will also occur from other defects with low detrapping energies, e.g., dislocations. At higher temperatures more and more D atoms detrap from the vacancies and at $400^{\circ} \mathrm{C}$ only a minor fraction of the initial amount is left in the implanted region. This remaining amount includes D trapped in larger vacancy clusters mainly produced during the implantation and grain boundaries. Previous study with identical D implantation in $\mathrm{W}$ showed that the implantation produced mostly monovacancies, while the production of larger vacancy clusters was seen to decrease fast with the increasing cluster size [19].

Figure 2 shows the remaining $\mathrm{D}$ amounts for annealings done in either vacuum or in $\mathrm{H}_{2}$ atmosphere. The $\mathrm{D}$ amounts are found to be identical for $2 \mathrm{~h}$ annealings at low temperatures. However, at $250^{\circ} \mathrm{C}$ the $\mathrm{D}$ amount in the samples annealed in $\mathrm{H}_{2}$ atmosphere drops rapidly below the vacuum annealing amount. In parallel, there is an increase in the trapped $\mathrm{H}$ amount in the implanted region. This behaviour is typical for hydrogen isotope exchange and has been observed previously during low energy plasma irradiation of $\mathrm{W}[6,7]$. Annealing at $200^{\circ} \mathrm{C}$ for $48 \mathrm{~h}$ further decreases the trapped D in samples annealed in both vacuum and $\mathrm{H}_{2}$ atmosphere. For $\mathrm{H}_{2}$ atmosphere annealing the remaining D amount is only $10 \%$ compared to the initially retained amount. Annealing 
at $250^{\circ} \mathrm{C}$ for $24 \mathrm{~h}$ in $\mathrm{H}_{2}$ atmosphere is sufficient to remove effectively all retained $\mathrm{D}$. At this temperature it may be that even a shorter annealing time would be enough.

Hence, the isotope exchange and $\mathrm{T}$ removal can be achieved by annealing in $\mathrm{H}_{2}$ atmosphere only, and no $\mathrm{H}$ irradiation is required. However, the effectiveness of the hydrogen exchange process in $\mathrm{H}_{2}$ gas annealing compared to $\mathrm{H}$ irradiation procedure is very low. The reason for this can be found by looking at the H-W system. The solution energy for $\mathrm{H}$ atoms in the $\mathrm{W}$ bulk compared to $\mathrm{H}$ the gas phase is about $1 \mathrm{eV}[23,24]$, which is among the highest ones for $\mathrm{H}$ in metals. Consequently, the equilibrium solute $\mathrm{H}$ concentration is very low for temperatures under $1000^{\circ} \mathrm{C}$. At $400^{\circ} \mathrm{C}$ the equilibrium $\mathrm{H}$ concentration in $\mathrm{W}$ is about $6 \times 10^{15} \mathrm{H} / \mathrm{cm}^{3}\left(\mathrm{H} / \mathrm{W} \sim 1 \times 10^{-7}\right)[25]$.

The potential energy barrier from the sample surface to the bulk is about $1.6 \mathrm{eV}$ [15]. Assuming this energy barrier, $10^{15} / \mathrm{cm}^{2}$ surface $\mathrm{H}$ coverage with a jump frequency of $10^{13} / \mathrm{s}$ we get a surface to bulk atomic $\mathrm{H}$ flux of $\sim 10^{11} /\left(\mathrm{cm}^{2} \mathrm{~s}\right)$ at $200^{\circ} \mathrm{C}$ and $\sim 10^{14} /\left(\mathrm{cm}^{2} \mathrm{~s}\right)$ at $300^{\circ} \mathrm{C}$. This substantial increase of the $\mathrm{H}$ flux at $300^{\circ} \mathrm{C}$ coincides with the clear drop in the $\mathrm{D}$ amount for $2 \mathrm{~h}$ annealing done in $\mathrm{H}_{2}$ atmosphere compared to vacuum annealing in Fig. 2. It is further observed that the $2 \mathrm{~h} \mathrm{H}_{2}$ atmosphere annealing at $200^{\circ} \mathrm{C}$ is not long enough for any isotope exchange to take place. However, the longer $24 \mathrm{~h}$ annealing at this temperature shows clear isotope exchange.

The isotope exchange has been simulated by Doyle et al [5], Barton et al [26] and Hodile et al [27]. These simulations give insight into the isotope exchange mechanism. Each isotope has a similar detrapping rate from traps which are mostly vacancies. The empty traps are then again most probably filled with the isotope with largest solute concentration around the traps. The annealing in $\mathrm{H}_{2}$ atmosphere keeps the concentration of $\mathrm{H}$ in the sample constant, while the detrapped $\mathrm{D}$ most probably diffuses out from the sample.

Even though the isotope exchange efficiency by $\mathrm{H}_{2}$ gas annealing is rather low, the $250^{\circ} \mathrm{C} 24 \mathrm{~h}$ annealing removed within the experimental accuracy all the retained $\mathrm{D}$. The JET ITER-Like $\mathrm{W}$ divertor $15 \mathrm{~h}$ vacuum annealing [1] at $350^{\circ} \mathrm{C}$ removed about $40 \%$ of the retained D. However, no comparison can be done between the present and the ITERLike $\mathrm{W}$ divertor annealing due to the very different $\mathrm{D}$ loading conditions, and hydride and deposit formation. However, the present results show that the $\mathrm{H}_{2}$ atmosphere gas annealing can be quite effective compared to vacuum annealing, and more research with the actual divertor material is needed. 


\section{Conclusions}

It is shown that annealing done in hydrogen atmosphere can be a promising method to remove tritium from the plasma-facing components in the present and future thermonuclear fusion devices. The hydrogen atmosphere annealing can also be used after vacuum annealing to further reduce the wanted isotope in the material. The low $\mathrm{H}$ solubility can partly be compensated with a longer annealing time to increase the isotopic exchange.

The $\mathrm{H}$ atmosphere annealing compared to vacuum annealing clearly lowers the temperature needed to remove a substantial amount of the trapped hydrogen isotopes.

\section{Acknowledgements}

This work has been carried out within the framework of the EUROfusion Consortium. The views and opinions expressed herein do not necessarily reflect those of the European Commission. 


\section{References}

[1] K. Heinola, J. Likonen, T. Ahlgren, S. Brezinsek, G. D. Temmerman, I. Jepu, G. Matthews, R. Pitts, A. Widdowson, and J. Contributors, "Long-term fuel retention and release in jet iterlike wall at iter-relevant baking temperatures," Nuclear Fusion, vol. 57, no. 8, p. 086024, 2017.

[2] K. Gibson, G. Counsell, C. Curran, M. Forrest, M. Kay, and K. Watkins, "The removal of codeposited hydrocarbon films from plasma facing components using high-power pulsed flashlamp irradiation," J. Nucl. Mater., vol. 337 - 339, p. 565, 2005.

[3] C. H. Skinner, A. A. Haasz, V. K. Alimov, N. Bekris, R. A. Causey, R. E. H. Clark, J. P. Coad, J. W. Davis, R. P. Doerner, M. Mayer, A. P. rev, J. Roth, and T. Tanabe, "Recent advances on hydrogen retention in iters plasma-facing materials: Beryllium, carbon, and tungsten," Fusion Science and Technology, vol. 54, no. 4, pp. 891-945, 2008.

[4] G. D. Temmerman, M. Baldwin, D. Anthoine, K. Heinola, A. Jan, I. Jepu, J. Likonen, C. Lungu, C. Porosnicu, and R. Pitts, "Efficiency of thermal outgassing for tritium retention measurement and removal in iter," Nuclear Materials and Energy, vol. 12, no. Supplement C, pp. $267-272$, 2017. Proceedings of the 22nd International Conference on Plasma Surface Interactions 2016, 22nd PSI.

[5] B. Doyle, W. Wampler, D. Brice, and S. Picraux, "Saturation and isotopic replacement of deuterium in low-z materials," Journal of Nuclear Materials, vol. 93-94, no. Part 2, pp. 551 $-557,1980$.

[6] J. Roth, T. Schwarz-Selinger, V. Alimov, and E. Markina, "Hydrogen isotope exchange in tungsten: Discussion as removal method for tritium," Journal of Nuclear Materials, vol. 432, no. 1, pp. 341 $-347,2013$.

[7] J. Barton, Y. Wang, T. Dittmar, R. Doerner, and G. Tynan, "Deuterium retention in tungsten after heavy ion damage and hydrogen isotope exchange in pisces," Nuclear Instruments and Methods in Physics Research Section B: Beam Interactions with Materials and Atoms, vol. 332, no. Supplement C, pp. 275 - 279, 2014. 21st International Conference on Ion Beam Analysis.

[8] R. Pitts, S. Carpentier, F. Escourbiac, T. Hirai, V. Komarov, A. Kukushkin, S. Lisgo, A. Loarte, M. Merola, R. Mitteau, A. Raffray, M. Shimada, and P. Stangeby, "Physics basis and design of the iter plasma-facing components," Journal of Nuclear Materials, vol. 415, no. 1, Supplement, pp. S957 - S964, 2011. Proceedings of the 19th International Conference on Plasma-Surface Interactions in Controlled Fusion.

[9] D. Kéroack and B. Terreault, "Laser desorption study of deuterium implanted in beryllium," Journal of Nuclear Materials, vol. 212-215, no. Part B, pp. 1443 - 1447, 1994. Fusion Reactor Materials.

[10] M. Poon, R. Macaulay-Newcombe, J. Davis, and A. Haasz, "Flux dependence of deuterium retention in single crystal tungsten," Journal of Nuclear Materials, vol. 307-311, no. Part 1, pp. $723-728,2002$.

[11] S. Kapser, M. Balden, T.F. da Silva, S. Elgeti, A. Manhard, K. Schmid, T. Schwarz-Selinger and U. von Toussaint, "Influence of sub-surface damage evolution on low-energy-plasma-driven deuterium permeation through tungsten," Nuclear Fusion, vol. 58, no. 5, p. 056027, 2018.

[12] L. Gao, W. Jacob, U. von Toussaint, A. Manhard, M. Balden, K. Schmid and T. Schwarz-Selinger, "Deuterium supersaturation in low-energy plasma-loaded tungsten surfaces," Nuclear Fusion, vol. 57, no. 1, p. 016026, 2017.

[13] T. Ahlgren, K. Heinola, E. Vainonen-Ahlgren, J. Likonen, and J. Keinonen, "Quantification of deuterium irradiation induced defect concentrations in tungsten," Nucl. Instr. and Meth. B, 
vol. 249, no. 1-2, pp. 436 - 439, 2006. Ion Beam Analysis - Proceedings of the Seventeenth International Conference on Ion Beam Analysis.

[14] E. Szilgyi, F. Pszti, G. Amsel, "Theoretical approximations for depth resolution calculations in IBA methods," Nucl. Instr. and Meth. B, vol. 100, pp. $103-121,1995$.

[15] K. Heinola and T. Ahlgren, "First-principles study of h on the reconstructed w(100) surface," Phys. Rev. B, vol. 81, no. 7, p. 073409, 2010.

[16] P. Alnot, A. Cassuto, and D. King, "Adsorption and desorption kinetics with no precursor trapping: Hydrogen and deuterium on w 100," Surface Science, vol. 215, no. 1, pp. 29 - 46, 1989.

[17] J. F. Ziegler, M. Ziegler, and J. Biersack, "Srim - the stopping and range of ions in matter (2010)," Nuclear Instruments and Methods in Physics Research Section B: Beam Interactions with Materials and Atoms, vol. 268, no. 11, pp. 1818 -1823, 2010. 19th International Conference on Ion Beam Analysis.

[18] T. Ahlgren and L. Bukonte, "Concentration dependent hydrogen diffusion in tungsten," Journal of Nuclear Materials, vol. 479, no. Supplement C, pp. 195 - 201, 2016.

[19] T. Ahlgren, K. Heinola, K. Vörtler, and J. Keinonen, "Simulation of irradiation induced deuterium trapping in tungsten," Journal of Nuclear Materials, vol. 427, no. 1 - 3, pp. 152 - 161, 2012.

[20] C. Becquart and C. Domain, "A density functional theory assessment of the clustering behaviour of he and h in tungsten," Journal of Nuclear Materials, vol. 386 - 388, no. 0, pp. 109 - 111 , 2009.

[21] K. Heinola, T. Ahlgren, K. Nordlund, and J. Keinonen, "Hydrogen interaction with point defects in tungsten," Phys. Rev. B, vol. 82, no. 9, p. 094102, 2010.

[22] P. Franzen, C. Garcia-Rosales, H. Plank, and V. Alimov, "Hydrogen trapping in and release from tungsten: Modeling and comparison with graphite with regard to its use as fusion reactor material," Journal of Nuclear Materials, vol. 241-243, no. Supplement C, pp. 1082 - 1086, 1997.

[23] R. Frauenfelder, "Solution and diffusion of hydrogen in tungsten," J. Vac. Sci. Technol., vol. 6, no. 3, p. 388, 1969.

[24] K. Heinola and T. Ahlgren, "Diffusion of hydrogen in bcc tungsten studied with first principle calculations," J. Appl. Phys., vol. 107, no. 11, p. 113531, 2010.

[25] R. Kirchheim, "Solid solutions of hydrogen in complex materials," vol. 59 of Solid State Physics, pp. 203 - 291, Academic Press, 2004.

[26] J. Barton, Y. Wang, R. Doerner, and G. Tynan, "Development of an analytical diffusion model for modeling hydrogen isotope exchange," Journal of Nuclear Materials, vol. 463, no. Supplement C, pp. 1129 - 1133, 2015. PLASMA-SURFACE INTERACTIONS 21.

[27] E. A. Hodille, Y. Ferro, N. Fernandez, C. S. Becquart, T. Angot, J. M. Layet, R. Bisson, and C. Grisolia, "Study of hydrogen isotopes behavior in tungsten by a multi trapping macroscopic rate equation model," Physica Scripta, vol. 2016, no. T167, p. 014011, 2016. 